\title{
Applying Count Models to Estimate the Tourism Demands and Recreation Benefits of Taijiang National Park
}

\author{
Chih-Ming Dong \\ Department of Recreation and Healthcare Management, \\ Chia Nan University of Pharmacy \& Science, Tainan City 71710, Taiwan; \\ Chien-Chi Lin \\ Department of Tourism, Food \& Beverage Management, \\ Chang Jung Christian University, Tainan City 71101, Taiwan
}

\begin{abstract}
In this study, a survey was conducted with tourists at Taijiang National Park. The results were analyzed using a t-test and one-way analysis of variance to determine whether the demographic variables of tourists exhibited significant differences in total annual travel costs, and then the travel cost method was applied to estimate the recreation benefits of Taijiang National Park. Regarding an empirical model for tourism demand at Taijiang National Park, this study used a truncated Poisson regression (TPOIS) model, truncated negative binomial regression model, and On-Site Poisson model to correct errors due to the truncation and endogenous stratification of the field samples. The results revealed the following: (1) The On-Site Poisson model yielded results that were superior to those yielded by the other two models and was thus more suitable for estimating the tourism demand at Taijiang National Park. (2) The three recreation benefits (consumer surplus, compensating variation, and equivalent variation) estimated by the TPOIS model were significantly greater than those estimated by the On-Site Poisson model. (3). Based on the estimation by the OnSite Poisson model, the price elasticity and income elasticity of the recreation demand at Taijiang National Park were -0.5423 and 0.3729, respectively. (4) Based on the estimation of the recreation benefits of Taijiang National Park by using the On-Site Poisson model, the consumer surplus was NT $\$ 4,167 /$ person/year.
\end{abstract}

Keywords: Taijiang National Park, Count model, Recreation Benefits, Travel Cost Method.

\section{INTRODUCTION}

National parks are established with the purposes of protecting their unique natural scenery, wildlife, and historical sites and providing people with areas for recreation and research. Thus, three main goals for establishing national parks are conservation, recreation, and research. Taijiang National Park was approved as Taiwan's eighth national park by the Executive Yuan on September 28, 2009. Numerous questions regarding the park still require further research and investigation because of the short time since its establishment. Particularly, assessing its overall recreation benefits is a top priority for operating and managing the park. The evaluation of recreation benefits is an essential basis for promoting the recreation businesses and improving environmental quality. However, because recreational resources possess the characteristics of "public goods," obtaining their price information from the market is often challenging, and this leads to difficulties in assessing their recreation benefits. Therefore, their benefits must be evaluated using estimation methods for nonmarket goods. At present, one of the commonly used methods for recreation benefit evaluation is the travel cost method (TCM), which estimates tourism demand function, whereby the use value of recreation is estimated by calculating tourists' consumer surplus (CS). Another approach is the contingent valuation 
method, which estimates the use and nonuse values of recreational environment restoration and protection. The main purpose of this study is to use the TCM to construct an effective evaluation model for assessing the recreation benefits of Taijiang National Park, and to estimate the average annual recreation benefits per capita, thereby providing a reference for the operation and management planning of Taijiang National Park.

\section{LITERATURE REVIEW}

Recreation benefits refer to the effects of satisfying people's specific needs (e.g., visual entertainment and rest). According to the definition by Shen (2005) from the perspective of recreational experience, recreation benefits are generated based on the distinct levels of satisfaction that tourists acquire from recreational experiences by engaging in recreational activities in recreational environments. The generation process is shown in Fig. 1.

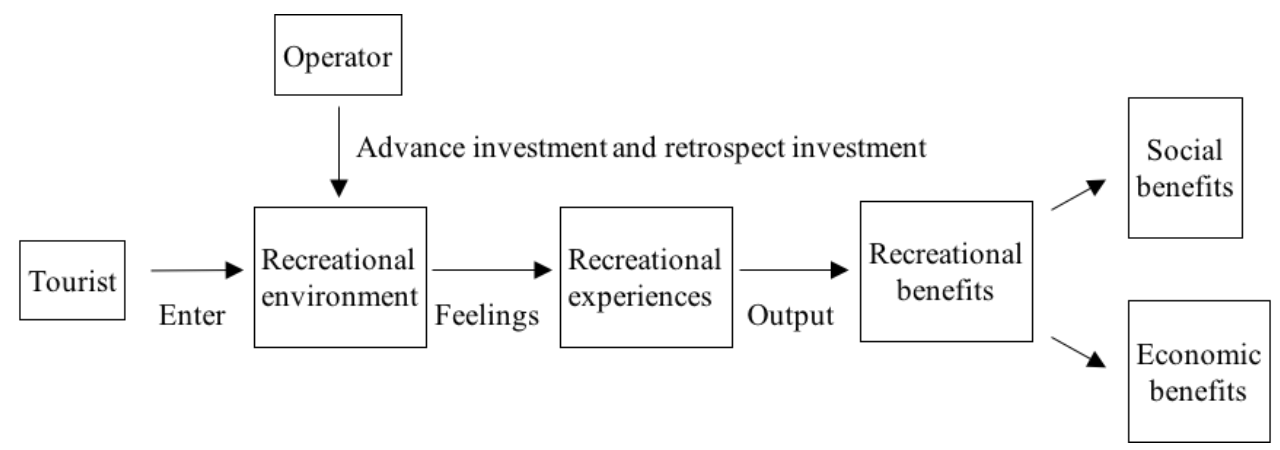

Figure 1. Generation of recreation benefits

Recreation benefits are theoretically the illusory and immeasurable effects produced by the spiritual gains and losses that satisfy people's psychological and physiological needs. Despite their immeasurability, these benefits can still be assessed using the resulting monetization of consumption behaviors in the relevant markets through alternative values such as alternative costs, opportunity costs, willingness to pay, and marginal utility. According to the benefit analysis of economic theories, the main methods for estimating nonmarket goods are divided into income compensation and expenditure function approaches. Particularly, the contingent valuation method based on the income compensation approach and the hedonic price method and TCM based on the "expenditure function approach" are the most commonly used [1]. The TCM calculates tourists' CS through tourism demand function and then estimates the recreation benefits of a reaction site. The following is a review and explanation of the TCM.

The concept of TCM was first proposed by Hotelling [2], who observed travel distance and tourism participation rate in different residential areas to derive the recreation demand function and to estimate recreation benefits. Clawson [3] and Knetsch [4] used CS to construct the recreation demand function, establishing the development of TCM. Its shortcomings were subsequently revised by many scholars [5,6], thereby enabling its wide application and discussion in academia. TCM has been widely applied to different tourism fields to assess the value of recreational resources [7-11]. In Taiwan, TCM has been used in numerous aspects of research in the past two decades, including national parks, forest recreation areas, festivals, and tourism and recreation attractions [12-22]. Based on the aforementioned literature, in TCM, tourists' travel costs are regarded as the price of using the resources by which the tourists' demands for the resources are estimated and the economic benefits of the recreational resources are determined.

Taijiang National Park was established in October 2009. Because of the short time since its establishment, the national park still has numerous problems that require further research and 
investigation. Studies on Taijiang National Park mostly focused on three aspects. (1) Conservation policies, behaviors, and mechanisms of the natural environment: For example, Cheng [23] explored the mechanism of wetland conservation management in Taijiang National Park on the basis of the concept of environmental trust; Kao [24] investigated the mangrove conservation policy of the Taijiang National Park Green Tunnel; and Chen [25] studied the park's environmental conservation behavior model. (2) National park development strategies, policies, operations and management strategies, and measures: For example, Zhuang [26] conducted a case study on the development strategies of Taijiang National Park; Li [27] conducted a case study on the black-faced spoonbill to explore the policies regarding Taijiang National Park; Wang [28] developed sustainable management strategies for ecotourism in Taijiang National Park; and Wang [29] analyzed the relevant fishery management measures for the sea area of Taijiang National Park. (3) The analysis of tourists' post-tour intentions: For example, Tsai [30] analyzed the post-tour intentions of tourists at Taijiang National Park. In view of the lack of studies on the recreation benefits of Taijiang National Park, an in-depth study on evaluating this topic is necessary.

\section{Research Participants}

\section{RESEARCH PARTICIPANTS AND METHODS}

Taijiang National Park was once a crucial navigation channel for the ancestors of Taiwanese people to cross the sea to Taiwan. It has witnessed the history of Taiwan's development from Zheng Chenggong, the Dutch, and the Qing dynasty over hundreds of years, and has also acted as a record of immigration, religion, trade, and war. In addition, the modern aquaculture, fishery, and salt industries, as well as the unique coastal terrain, make Taijiang National Park the only national park in Taiwan to contain international-class wetlands, human history, ecological conservation, and economic industries. Taijiang National Park has two internationalclass wetlands (Zengwun Estuary and Shicao Wetlands) and two national-class wetlands (Qigu Salt Field and Yanshui Estuary Wetlands). The land territory of the park includes the coastal public land from Yanshui River to Zengwun River in Tainan City, the black-faced spoonbill reserve, and Qigu Lagoon. The 4,905-hectare area emphasizes three characteristics, namely the breeding of biodiversity in wetlands, ancestral immigration and development history, and the cultures of fishery and salt industries. The sea area of the park includes the area with a $20-\mathrm{m}$ depth contour along the coast, as well as that with a 20-m depth contour from Yanshui River to the south end of Dongji Island that forms a 5-km wide, 54-km long sea area. This area is the Dongji Island-Lu Er Men section in the major navigation channel that the ancestors of the Han people used to cross the sea to Taiwan, covering an area of 34,405 hectares and yielding a total area of 39,310 hectares.

\section{Research Methods}

The basic concept of TCM is to consider that consumers' total travel cost to their respective tourist destinations reflects their budget for engaging in recreational activities when they arrive. In general, those with higher travel costs have lower demands and thus meet the law of demand. Assuming that the consumers' recreation utility is affected by the number of travels ( $\left.{ }^{q}\right)$, the cost of each travel $\left({ }^{p}\right)$, and the price of synthetic goods $(Z)$, then under the restriction of income $\left({ }^{Y}\right)$, the consumers' utility maximization problem (UMP) is as follows:

$\begin{array}{ll}\operatorname{Max} & U(Z, q) \\ \text { S.t. } & Z+p q=Y\end{array}$

Solving the UMP in Equation (1) can obtain the consumers' tourism demand function for the tourist destination: 
$q^{*}=q^{*}(p, Y)$

In empirical research, the independent variables affecting tourism demands include tourism costs and individual socioeconomic characteristic variables; thus, the following regression model can be established:

$q=f\left(x_{1}, x_{2}, \cdots, x_{n}, p, Y\right)$

where $x_{1}, x_{2}, \ldots, x_{n}$ represent individual socioeconomic characteristic variables (e.g. gender, age, and education level), ${ }^{p}$ represents tourism costs, and $Y$ represents income.

In terms of value measurement, utility is used as an indicator of benefit measurement when the price of goods or income changes. However, because utility cannot be directly observed, the monetization of utility is required for its application, and the concept of surplus is used to measure recreation benefits. Therefore, once the tourists' individual tourism demand function

$q$ is estimated, it is integrated to yield CS, which can be used as the recreation economic benefits of the recreation site. Its calculation is as follows:

$\mathrm{CS}=\int_{p_{L}}^{p_{H}} f\left(x_{1}, x_{2}, . ., x_{n}, p, Y\right) d p$

In the equation, $f\left(x_{1}, x_{2, . .,}, x_{n}, p, Y\right)$ represents the tourism demand function, $p_{H}$ represents the highest travel expenses in all samples, and ${ }^{p_{L}}$ represents the lowest travel expenses in all samples.

\section{Empirical Model for Tourism Demands}

Because the respondents of the sample survey consisted of tourists in Taijiang National Park who have visited the park at least once, the dependent variable in the demand function-the number of trips-was greater than 0 and at least equal to 1 , which was consistent with the data characteristics of independent and nonnegative integers that a count model possesses. In addition, the number of trips in the questionnaire was defined as "the number of trips to Taijiang National Park in the past year;" thus, it possesses the characteristics of a specific unit period. The number of trips is a zero-truncated nonnegative integer; thus, the sample data were zero-truncated. Based on these data characteristics, the truncated Poisson (TPOIS) regression model was a more suitable analytical instrument for this study. However, the application of the Poisson regression model should satisfy the condition that each event occurs independently of each other within a specific period, and the mean value should be equal to the variance. The problem of overdispersion occurs if the variance of the sample data is greater than the mean value. In the event of considerable data variation in each surveyed tourist, corrections are mostly conducted using a negative binomial (NB) regression model. Estimating the results through the NB regression model yields an estimated $\alpha \alpha$ value. An $\alpha$ value that is significantly greater than 0 indicates the presence of overdispersion in the Poisson model, and the NB regression model is a more appropriate instrument to estimate the tourists' recreation benefits. However, because the data in this study were zero-truncated, a truncated negative binomial (TNB) regression model was adopted. Because tourists who frequently participate in recreational activities have higher interview rates, this produced problems of endogenous stratification; thus, some scholars proposed the On-Site Poisson model that can simultaneously solve sample data truncation and endogenous stratification. The three count models used in this study are illustrated as follows. 


\section{TPOIS Model}

The dependent variable in this study is the number of trips to Taijiang National Park $(q)$, which is a nonnegative integer. Therefore, the Poisson model for the tourists' tourism demand at Taijiang National Park can be expressed as follows:

$$
f(x=q)=\frac{\exp (-\lambda) \lambda^{q}}{q !}
$$

where $\lambda$ is the mean and variance of $q$, and is often expressed as follows:

$\lambda=E(q)=\operatorname{Var}(q)=\exp (x \beta)$

where $x$ represents an exogenous variable matrix (including individual socioeconomic characteristic variables, e.g., gender, age, and education level, as well as travel costs and income), and $\beta$ represents the parameter vector corresponding to the exogenous variables. Because the sample data in this study were zero-truncated, if the standard Poisson model was multiplied by $[1 / 1-\exp (-\lambda)]$, the estimation error caused by the tourists who were not present can be removed. The truncated Poisson model is as follows:

$$
f(X=q \mid q>0)=\frac{\exp (-\lambda) \lambda^{q}}{q !}\left[\frac{1}{1-\exp (-\lambda)}\right]
$$

\section{TNB Model}

Poisson distribution is a distribution model for nonnegative integers. Sample data where the mean value does not equal the variance result in problems of overdispersion, which can be corrected using the NB distribution model. The NB model is as follows:

$$
f(X=q)=\frac{\gamma\left(q+\frac{1}{\alpha}\right)}{\gamma(q+1) \gamma\left(\frac{1}{\alpha}\right)}(\alpha \lambda)^{q}(1+\alpha \lambda)^{-\left(q+\frac{1}{\alpha}\right)}
$$

where $\gamma()$ represents the Gamma distribution, and $\alpha$ represents the coefficient of disturbance and is greater than 0 . The mean and variance of number of trips $(q)$ possess the following features:

$\lambda=E(q)=\exp (x \beta)$

$\operatorname{Var}(q)=\lambda(1+\alpha \lambda)$

If the sample data are zero-truncated, the TNB model can be corrected as follows:

$$
f(X=q \mid q>0)=\frac{\gamma\left(q+\frac{1}{\alpha}\right)}{\gamma(q+1) \gamma\left(\frac{1}{\alpha}\right)}(\alpha \lambda)^{q}(1+\alpha \lambda)^{-\left(q+\frac{1}{\alpha}\right)} \cdot\left[\frac{1}{1-(1+\alpha \lambda)^{-\frac{1}{\alpha}}}\right]
$$

\section{On-Site Poisson Model}

If the sampled respondents are on-site tourists at Taijiang National Park, this leads to the endogenous stratification; that is, tourists who frequently visit Taijiang National Park have a higher probability of being interviewed, which is a problem that cannot be solved even with 
the use of TPOIS and TNB regression models. Therefore, some scholars have proposed the OnSite Poisson model that can simultaneously solve sample data truncation and endogenous stratification. Assuming that $g(q)$ is the probability density function of the number of tourists' visits in Taijiang National Park, the conditional probability density function is as follows [31]:

$g(q \mid q>0)=\frac{g(q)}{P(q>0)}$

The probability of the number of visits $h(j)$ of the interviewed tourists' in the $j$-th trip can be expressed as follows:

$$
h(j)=\frac{j \cdot g(j)}{\sum_{i=1}^{\infty} i \cdot g(i)}=\frac{j \cdot g(j)}{E(q)}
$$

Substituting Equation (11) into Equation (12) yields

$$
h(j \mid j>0)=\frac{j \frac{g(j)}{P(j>0)}}{\sum_{i=1}^{\infty} i \frac{g(i)}{P(j>0)}}=\frac{j \cdot g(j)}{\sum_{i=1}^{\infty} i \cdot g(i)}=\frac{j \cdot g(j)}{E(q)}=h(j)
$$

According to Equation (13), under the on-site survey sampling at Taijiang National Park and the resulting endogenous stratification, the tourism demands of the respondents visiting the national park should be subjected to inverse weighting through the expected value of number of trips. Let $g(q)$ be the distribution of individual tourism attributes. By substituting the original Poisson model (Equation 5) and the expected value $E(q)=\lambda$ into the aforementioned equation, the probability distribution of the On-Site Poisson model with truncated and endogenous stratification characteristics can be derived, as shown in the following equation:

$h(q \mid q>0)=\frac{\exp (-\lambda) \lambda^{q-1}}{(q-1) !}=\frac{\exp (-\lambda) \lambda^{w}}{w !}, \quad w=q-1(14$

Through the likelihood functions of the three models from Equations (7), (10), and (14), and combining the maximum likelihood estimate with Equation (3), the tourism demands of the tourists visiting Taijiang National Park can be estimated.

\section{Research Instruments}

To construct the tourism demand function model for the tourists, an empirical analysis was conducted on the basis of the questionnaire survey results. The questionnaire content referenced Chen and Lin [32] and included the respondents' demographic information, recreational behaviors and travel expenses, their satisfaction toward Taijiang National Park, and their post-tour intention, to estimate the resulting recreation benefits of the historical site.

\section{Respondents' Demographic Information}

The respondents' demographic information consisted of a total of nine items, which included gender, age, education level, marital status, occupation, average individual monthly income, working days, average family monthly income, and residential area. 


\section{Respondents' Recreational Behaviors and Travel Expenses}

The items in this section were developed based on the actual conditions of the respondents' individual travel experiences. They consisted of eight items: the number of trips to Taijiang National Park in the past year, means of transportation during the trips, duration of travel time, duration of stay, and travel expenses.

\section{Respondents' Satisfaction with Taijiang National Park and Post-Tour Intention}

This section consisted of three items, namely the respondents' satisfaction toward the tourism activities at Taijiang National Park, whether they will engage in the activities again, and whether they will recommend the activities to others.

\section{Questionnaire Distribution and Response}

\section{RESULTS AND DISCUSSION}

The survey was conducted between April and August 2017. A total of 300 questionnaires were distributed at Sicao Dazhong Temple, Liukong Service Station and Visitor Center, and the black-faced spoonbill ecological reserve, and 275 valid questionnaires were returned, yielding a valid response rate of $91.6 \%$. If calculated under the $95 \%$ confidence level according to the Churchill equation, the allowed estimation error for this study was approximately 5.9\% (please see the Appendix for the calculation).

\section{Sample Structure Analysis of Respondents}

Descriptive statistics were mainly used for the preliminary discussion of the respondents' demographic information, with the main contents being the respondents' gender, age, education level, marital status, occupation, average individual monthly income, working days, average family monthly income, and residential area. Table 1 shows the sample structure for the tourists visiting Taijiang National Park.

Table 1 illustrates that among the 275 valid samples, men and women accounted for $43.3 \%$ and $56.7 \%$, respectively. In terms of age, respondents aged 21-30 accounted for the highest proportion (36.4\%), followed by those in the 31-40 age range (32.1\%); the average age of all respondents was 34.6 years. In terms of education level, respondents with a university or college diploma accounted for $68.2 \%$, followed by those with a general and vocational high school diploma (21.4\%), indicating that the respondents' education level was mostly between high school (general and vocational) and university or college and these respondents accounted for $89.6 \%$ of the overall respondents. Single and married respondents accounted for $49.0 \%$ and $51.0 \%$, respectively. In terms of occupation, the respondents (48.9\%) were mostly in the business services industry, followed by $16.8 \%$ who were students. In terms of average individual monthly income, respondents with an income range of NT\$30,001-40,000 accounted for the most (23.2\%), followed by those with an income of NT $\$ 20,001-30,000$ (21.8\%); the mean individual monthly income was NT\$31,873.2. Respondents with 21-25 working days per month accounted for the most (53.2\%), followed by those who work for 10 days or less (16.4\%); the average number of working days was 20.2. In terms of average family monthly income, most respondents $(32.1 \%)$ fell under the range of NT\$50,001-70,000, followed by those in the NT $\$ 70,001-100,000$ range (22.5\%); the mean family monthly income was NT $\$ 66,836.9$. Finally, in terms of residential area, most tourists came from southern Taiwan (49.6\%), followed by those who lived in central Taiwan (28.2\%).

Table 1 Sample structure analysis of respondents

\begin{tabular}{llcl}
\hline Items & Options & $\%$ & M \\
\hline \multirow{2}{*}{ Gender } & Men & 43.3 & - \\
& Women & 56.7 & - \\
\hline
\end{tabular}




\begin{tabular}{|c|c|c|c|}
\hline \multirow{5}{*}{ Age } & 20 years old or younger & 3.6 & \multirow{5}{*}{34.6} \\
\hline & $21-30$ years old & 36.4 & \\
\hline & $31-40$ years old & 32.1 & \\
\hline & $41-50$ years old & 22.5 & \\
\hline & 50 years old or older & 5.4 & \\
\hline \multirow{4}{*}{ Education Level } & Junior high school or lower & 0.0 & \multirow{4}{*}{-} \\
\hline & General and vocational high school & 21.4 & \\
\hline & University / College & 68.2 & \\
\hline & Master's / Ph.D. & 10.4 & \\
\hline \multirow{2}{*}{ Marital Status } & Single & 49.0 & \multirow{2}{*}{-} \\
\hline & Married & 51.0 & \\
\hline \multirow{7}{*}{ Occupation } & Student & & \multirow{7}{*}{-} \\
\hline & Military, public, and teaching personnel & $\begin{array}{c}16.8 \\
89\end{array}$ & \\
\hline & Health care workers and self-employed & $\begin{array}{r}8.9 \\
125\end{array}$ & \\
\hline & Business services & 12.5 & \\
\hline & Housekeeper, retired, or unemployed & $\begin{array}{c}48.9 \\
72\end{array}$ & \\
\hline & Agriculture, forestry, fishery, and animal & 7.2 & \\
\hline & husbandry industries and others & 5.1 & \\
\hline \multirow{7}{*}{$\begin{array}{l}\text { Average Individual } \\
\text { Monthly Income }\end{array}$} & NT $\$ 10,000$ or lower & 13.2 & \multirow{7}{*}{31873.2} \\
\hline & NT\$10,001-20,000 & 12.1 & \\
\hline & NT $\$ 20,001-30,000$ & 21.8 & \\
\hline & NT\$30,001-40,000 & 23.2 & \\
\hline & NT $\$ 40,001-50,000$ & 16.1 & \\
\hline & NT\$50,001-60,000 & 6.8 & \\
\hline & NT $\$ 60,001$ or higher & 6.8 & \\
\hline \multirow{5}{*}{ Working Days } & Fewer than 10 days & 16.4 & \multirow{5}{*}{20.2} \\
\hline & $10-15$ days & 2.2 & \\
\hline & 15-20 days & 12.1 & \\
\hline & 21-25 days & 53.2 & \\
\hline & 26 days or more & 16.1 & \\
\hline \multirow{7}{*}{$\begin{array}{l}\text { Average Family } \\
\text { Monthly Income }\end{array}$} & NT $\$ 20,000$ or lower & 1.4 & \multirow{7}{*}{66836.9} \\
\hline & NT $\$ 20,001-30,000$ & 4.3 & \\
\hline & NT $\$ 30,001-40,000$ & 7.9 & \\
\hline & NT $\$ 40,001-50,000$ & 18.2 & \\
\hline & NT $\$ 50,001-70,000$ & 32.1 & \\
\hline & NT\$70,001-100,000 & 22.5 & \\
\hline & NT $\$ 100,001$ or higher & 13.6 & \\
\hline \multirow{5}{*}{ Residential Area } & Northern Taiwan & 19.6 & \multirow{5}{*}{-} \\
\hline & Central Taiwan & 28.2 & \\
\hline & Southern Taiwan & 49.6 & \\
\hline & Eastern Taiwan & 2.2 & \\
\hline & Overseas & 0.4 & \\
\hline
\end{tabular}

Source: Compiled by this study 
Table 2 Analysis of respondents' recreational behaviors and travel expenses

\begin{tabular}{|c|c|c|c|c|}
\hline Items & Options & $\%$ & M & SD \\
\hline \multirow{5}{*}{ Number of trips } & Once & 73.0 & \multirow{5}{*}{1.4} & \multirow{5}{*}{0.76} \\
\hline & Twice & 22.9 & & \\
\hline & Thrice & 1.5 & & \\
\hline & 4 Times & 0.7 & & \\
\hline & 5 Times or more & 1.9 & & \\
\hline \multirow{5}{*}{$\begin{array}{l}\text { Duration of tourists' travel } \\
\text { time }\end{array}$} & Less than $1 \mathrm{~h}$ & 26.6 & \multirow{5}{*}{2.1} & \multirow{5}{*}{1.5} \\
\hline & $1-2 \mathrm{~h}$ & 40.8 & & \\
\hline & ${ }^{1} 2-4 \mathrm{~h}$ & 29.9 & & \\
\hline & $4-6 \mathrm{~h}$ & 1.8 & & \\
\hline & $6 \mathrm{~h}$ or more & 0.9 & & \\
\hline \multirow{6}{*}{$\begin{array}{l}\text { Tourists' transportation } \\
\text { expenses }\end{array}$} & NT $\$ 500$ or lower & 40.7 & \multirow{6}{*}{676.8} & \multirow{6}{*}{454.6} \\
\hline & NT\$501-1,000 & 41.8 & & \\
\hline & NT $\$ 1,001-1,500$ & 11.1 & & \\
\hline & NT\$1,501-2,000 & 5.4 & & \\
\hline & NT $\$ 2,001-3,000$ & 0.7 & & \\
\hline & NT $\$ 3,001$ or more & 0.3 & & \\
\hline \multirow{7}{*}{ Tourists' duration of stay } & Less than $1 \mathrm{~h}$ & 14.3 & \multirow{7}{*}{2.1} & \multirow{7}{*}{3.5} \\
\hline & $1-2 \mathrm{~h}$ & 62.1 & & \\
\hline & $2-4 \mathrm{~h}$ & 20.7 & & \\
\hline & $4-6 \mathrm{~h}$ & 1.8 & & \\
\hline & $6-8 \mathrm{~h}$ & 0.0 & & \\
\hline & 1 day & 0.7 & & \\
\hline & 2 days or more & 0.4 & & \\
\hline \multirow{6}{*}{$\begin{array}{l}\text { Tourists' food and } \\
\text { accommodation expenses }\end{array}$} & NT $\$ 500$ or lower & 44.3 & \multirow{6}{*}{718.1} & \multirow{6}{*}{539.4} \\
\hline & NT\$501-1,000 & 32.1 & & \\
\hline & NT $\$ 1,001-1,500$ & 12.5 & & \\
\hline & NT $\$ 1,501-2,000$ & 7.9 & & \\
\hline & NT $\$ 2,001-3,000$ & 2.1 & & \\
\hline & NT $\$ 3,001$ or more & 1.1 & & \\
\hline \multirow{6}{*}{ Tourists' other expenses } & NT $\$ 500$ or lower & 56.1 & \multirow{6}{*}{606.2} & \multirow{6}{*}{515.3} \\
\hline & NT\$501-1,000 & 35.2 & & \\
\hline & NT $\$ 1,001-1,500$ & 1.7 & & \\
\hline & NT $\$ 1,501-2,000$ & 3.5 & & \\
\hline & NT $\$ 2,, 001-3,000$ & 2.8 & & \\
\hline & NT $\$ 3,001$ or higher & 0.7 & & \\
\hline
\end{tabular}

Source: compiled by this study

\section{Respondents' Recreational Behaviors and Travel Expenses}

Table 2 shows that in terms of the number of trips, most tourists $(73.0 \%)$ had only visited Taijiang National Park once, followed by those who had visited twice $(22.9 \%)$; the average number of trips was $1.4( \pm 0.76)$. Because Taijiang National Park was established in October 2009 , its short time of establishment and low visibility among tourists were the reasons why most tourists were first-time visitors. The duration of travel time for most respondents was 1$2 \mathrm{~h}(40.8 \%)$, followed by $2-4 \mathrm{~h}$ (29.9\%); the average travel time was $2.1 \mathrm{~h}( \pm 1.5)$. This result echoed the sampled tourists in the aforementioned analysis who were mostly from southern Taiwan. The transportation expenses for most tourists fell in the range of NT\$501-1,000 $(41.8 \%)$, followed by NT $\$ 500$ or less $(40.7 \%)$; the average transportation expenses were NT\$676.8 ( \pm 454.6$)$. The duration of stay for most tourists was 1-2 h (62.1\%), followed by 2-4 $\mathrm{h}(20.7 \%)$; the average stay duration was $2.1 \mathrm{~h}( \pm 3.5)$. Most tourists had a food and accommodation expense of NT $\$ 500$ or less (44.3\%), followed by those who spent NT $\$ 501-$ 1,000 (32.1\%); the average food and accommodation expenses were NT\$718.1 $( \pm 539.4)$. In terms of other expenses, most tourists spent NT $\$ 500$ or less $(56.1 \%)$, followed by those with an expense of NT\$501-1,000 (35.2\%); the average expenses for other items were NT\$606.2 $( \pm$ 515.3). 
Among the tourists' expenses for various items, the "average expenses for other items per trip" were the lowest (NT\$606.2); the "average food and accommodation expenses per trip" were the highest (NT\$718.1). In summary, most tourists spent more on food and accommodation and had fewer other expenses.

\section{Difference Analysis of the Respondents' Demographic Variables and the Construct of Total Annual Travel Costs}

A $t$-test and one-way analysis of variance were performed in this section to examine the differences in total annual travel costs in relation to the respondents' demographic variables. The results are shown in Table 3. For the estimation of the tourists' annual travel costs, this study totaled their transportation expenses, food and accommodation expenses, other expenses, and opportunity costs, and multiplied them with the annual number of trips to produce an estimated value. The respondents' gender exhibited significant differences in "total annual travel costs," and the results of the independent sample $t$-test showed that men's expenses were significantly higher than women's. A speculated reason for this result was that men might be more interested in outdoor activities than women. Different education levels also displayed significant differences in "total annual travel costs," with the Scheffe post-hoc test indicating that respondents with an education level of "Master's or higher" had higher total annual costs than those with a "university / college" and "general and vocational high school" diploma. A possible reason could be that respondents with higher education levels also had relatively high socioeconomic statuses; thus, they were willing to spend more when they participated in the tours at Taijiang National Park. Respondents with different monthly incomes exhibited significant differences in "total annual travel costs," with the Scheffe posthoc test indicating that respondents with a monthly income of NT\$50,001-60,000 had higher total travel costs than those with an income of NT $\$ 10,000$ or less.

\section{Empirical Model Estimation of Tourism Demands}

NLOGIT 5.0 metrology software was used in this study for estimation, and the tourism demand function of Taijiang National Park was constructed using TPOIS, TNB, and On-Site Poisson models. The selection of independent variables references studies by Chen and Lin [31], and consisted of tourists' gender, age, marital status, monthly income, average travel costs per trip, and satisfaction. Table 4 shows the names and definitions of the aforementioned variables.

Table 5 shows the estimation results of the three count models. The test results of the TNB model indicate that the $\alpha$ value was positive and the null hypothesis could not be rejected with a significance level of 5\%. Therefore, the data collected in this study did not exhibit overdispersion. As a result, estimating the tourism demand with the TPOIS and On-Site Poisson models was more appropriate.

Table 3 Difference analysis on demographic variables and total annual travel costs Demographic Variables Results of Difference Analysis

\begin{tabular}{cc}
\hline Demographic Variables & Results of Difference Analysis \\
\hline Gender & $\begin{array}{c}\mathrm{T}=2.080 \quad \mathrm{P}=.039 * * \\
\text { T-test Men }>\text { Women }\end{array}$ \\
\hline Age & $\mathrm{F}=1.400 \mathrm{P}=.234$ \\
\hline Education Level & $\mathrm{F}=7.804 \mathrm{P}=.001^{* * *}$ \\
Scheffe test $\mathrm{C}>\mathrm{A} ; \mathrm{C}>\mathrm{B}$
\end{tabular}

Note: ${ }^{* *} P \leq 0.05,{ }^{* * *} P \leq 0.01 ; \quad$ A: general and vocational high school B: university / college C: Master's or higher D: NT\$10,000 or lower E: NT\$50,001-60,000 
Table 4 Definitions of various variables in the empirical model

\begin{tabular}{cl}
\hline Variables & \multicolumn{1}{c}{ Definitions } \\
\hline Gender & $\begin{array}{l}\text { Dummy variable for gender: 0 represents "male," 1 represents } \\
\text { "female" }\end{array}$ \\
\hline Age & Age (unit: years) \\
\hline Marry & $\begin{array}{l}\text { Dummy variable for marital status: 0 represents "single," } 1 \\
\text { represents "married" }\end{array}$ \\
\hline Income & Individual monthly income (unit: NT\$) \\
\hline P & Average travel costs per trip (unit: NT\$) \\
\hline Satisfy & $\begin{array}{l}\text { Tourists' satisfaction, with 5, 4, 3, 2, and 1 each representing } \\
\text { "strongly satisfied," “satisfied," “neither satisfied nor dissatisfied," } \\
\text { “dissatisfied," and strongly dissatisfied" }\end{array}$ \\
\hline
\end{tabular}

The TPOIS model shows that the coefficient of gender was negative and its $t$-value reached a significance level of $10 \%$, indicating that men had a higher number of trips compared with women. This result may be related to men's higher interest in natural ecological activities than women. The coefficient for marital status "Marry" was also negative with a $t$-value that reached a significance level of $10 \%$, indicating a higher number of trips for single individuals than that for married individuals. A possible reason for this could be that single individuals are less bound by their families, and thus have more opportunities to participate in the ecological tours at Taijiang National Park. The coefficient of travel costs (P) was negative and its $t$-value achieved a significance level of $1 \%$, indicating a drop in the number of trips following an increase in tourists' travel costs. According to the On-Site Poisson model, gender had a negative coefficient and its $t$-value reached a significance level of $5 \%$, meaning that men took a higher number of trips than women. The coefficient for marital status (Marry) was also negative and its $t$ value achieved a significance level of $10 \%$, indicating that single individuals took more trips than married individuals. Individual monthly income (Income) had a negative coefficient with a $t$-value that reached a significance level of $10 \%$, indicating that individuals with higher monthly income took a higher number of trips than those with lower monthly income. The coefficient of travel costs (P) was negative and its $t$-value achieved a significance level of $1 \%$, indicating a decline in tourists' number of trips following a rise in their travel costs. Although satisfaction (Satisfy) had a positive coefficient (indicating that higher satisfaction leads to a higher number of trips), the null hypothesis that the coefficient is 0 could not be rejected at a significance level of $10 \%$. A possible reason could be that a high proportion of tourists were first-time visitors and that some tourists gave a higher satisfaction rating to Taijiang National Park. 
Table 5 Estimation results of the tourism demand models of Taijiang National Park

\begin{tabular}{|c|c|c|c|c|}
\hline & & TPOIS & TNB & On-Site POIS \\
\hline & Constant Term & $\begin{array}{c}-2.84 \mathrm{E}-01 \\
(-0.38)\end{array}$ & $\begin{array}{c}-8.95 E-01 \\
(-0.78)\end{array}$ & $\begin{array}{c}-8.64 \mathrm{E}-01 \\
(-1.09)\end{array}$ \\
\hline & Gender & $\begin{array}{c}-3.96 \mathrm{E}-01 \\
(-1.90)^{*}\end{array}$ & $\begin{array}{c}-4.30 \mathrm{E}-01 \\
(-1.49)\end{array}$ & $\begin{array}{c}-4.38 E-01 \\
(-2.00)^{* *}\end{array}$ \\
\hline & Age & $\begin{array}{c}3.73 \mathrm{E}-03 \\
(0.25)\end{array}$ & $\begin{array}{c}5.04 \mathrm{E}-03 \\
(0.23)\end{array}$ & $\begin{array}{c}4.43 \mathrm{E}-03 \\
(0.29)\end{array}$ \\
\hline \multirow[t]{8}{*}{$\begin{array}{c}\text { Travel Expenses } \\
\text { and Socioeconomic } \\
\text { Variables }\end{array}$} & Marry & $\begin{array}{c}-4.35 \mathrm{E}-01 \\
(-1.76)^{*}\end{array}$ & $\begin{array}{c}-4.53 E-01 \\
(-1.09)\end{array}$ & $\begin{array}{c}-4.86 \mathrm{E}-01 \\
(-1.87)^{*}\end{array}$ \\
\hline & Income & $\begin{array}{c}1.05 \mathrm{E}-05 \\
(1.56)\end{array}$ & $\begin{array}{c}1.18 \mathrm{E}-05 \\
(1.25)\end{array}$ & $\begin{array}{c}1.17 \mathrm{E}-05 \\
(1.65)^{*}\end{array}$ \\
\hline & $\mathrm{P}$ & $\begin{array}{l}-2.2 \mathrm{E}-04 \\
(-2.64)^{* * *}\end{array}$ & $\begin{array}{l}-2.5 \mathrm{E}-04 \\
(-2.40)^{* *}\end{array}$ & $\begin{array}{l}-2.4 \mathrm{E}-04 \\
(-2.78)^{* * *}\end{array}$ \\
\hline & Satisfy & $\begin{array}{c}6.24 \mathrm{E}-02 \\
(0.40)\end{array}$ & $\begin{array}{c}8.44 \mathrm{E}-02 \\
(0.36)\end{array}$ & $\begin{array}{c}6.90 \mathrm{E}-02 \\
(0.42)\end{array}$ \\
\hline & Log likelihood & -211.498 & -208.102 & -214.529 \\
\hline & $\begin{array}{l}\text { Restricted log } \\
\text { Likelihood }\end{array}$ & -343.713 & -211.498 & -225.609 \\
\hline & $\begin{array}{c}\text { Chi- } \\
\text { squared }\end{array}$ & $264.43^{* * *}$ & $6.792^{* *}$ & $22.159^{* * *}$ \\
\hline & $\alpha$ & & $\begin{array}{c}8.80 \mathrm{E}-01 \\
(1.08)\end{array}$ & \\
\hline
\end{tabular}

Note: the values in brackets are $t$-values. * indicates significance at a significance level of $10 \%$, ** indicates significance at a significance level of $5 \%$, and $* * *$ indicates significance at a significance level of $1 \%$.

The tourism demand models show that the variable symbols were approximately consistent with expectations. Although the TPOIS and On-Site Poisson models passed the goodness-of-fit test and yielded similar results, the significance of the coefficients of travel costs and socioeconomic variables demonstrated that the On-Site Poisson model had a superior explanatory power compared with the TPOIS model. In addition, the On-Site Poisson model also corrected the errors of truncation and automatic stratification; thus, the On-Site Poisson model was more suitable for evaluating the tourism demands of Taijiang National Park.

After exploring the demand models, the price elasticity and income elasticity for the recreation demands of Taijiang National Park were further estimated. The price elasticity $\left(E_{d}\right)$ and income elasticity $\left(E_{I}\right)$ were each defined as follows:

$$
\begin{aligned}
& \mathrm{CS}_{\mathrm{i}}=\int_{\mathrm{C}^{0}}^{\infty} \mathrm{e}^{\beta_{0}+\beta_{1} \mathrm{c}} \mathrm{dc}=\left[\frac{\mathrm{e}^{\beta_{0}+\beta_{1} \mathrm{c}}}{\beta_{1}}\right]_{\mathrm{c}=\mathrm{c}_{0}}^{\mathrm{c} \rightarrow \infty}=-\frac{\mathrm{x}_{\mathrm{i}}}{\beta_{1}} \\
& E_{I}=\frac{\Delta q / q}{\Delta Y / Y}=\frac{\Delta q}{\Delta Y} \cdot \frac{Y}{q}
\end{aligned}
$$


where $P$ is the travel costs, the number of trips $q$ obeys the exponential demand function and $q=\exp \left(\beta_{o}+\beta_{1} P+\beta_{2} Y\right) \mathrm{x}=\mathrm{e}^{\beta_{0}+\beta_{1} \mathrm{c}}, \beta_{o} \beta_{0}$ represents the constant term, $\beta_{1} \beta_{1}$ is the estimated coefficient of travel costs, and $\beta_{2}$ represents the estimated coefficient of income. Substituting the number of trips $q$ into Equations (15) and (16) yields the price elasticity and income elasticity of demand:

$$
\begin{aligned}
& \mathrm{CS}_{\mathrm{i}}=\int_{\mathrm{C}^{0}}^{\infty} \mathrm{e}^{\beta_{0}+\beta_{1} \mathrm{c}} \mathrm{dc}=\left[\frac{\mathrm{e}^{\beta_{0}+\beta_{1} \mathrm{c}}}{\beta_{1}}\right]_{\mathrm{c}=\mathrm{c}_{0}}^{\mathrm{c} \rightarrow \infty}=-\frac{\mathrm{x}_{\mathrm{i}}}{\beta_{1}} \\
& E_{I}=q \cdot \beta_{2} \cdot \frac{Y}{q}=\beta_{2} Y
\end{aligned}
$$

Table 6 Elasticity of variables under the On-Site Poisson model

\begin{tabular}{c|ccc}
\hline Items & Coefficient Value & $\begin{array}{c}\text { Average Travel Cost } \\
\text { per Person } \\
\text { (Income) }\end{array}$ & Elasticity \\
\hline $\mathrm{P}$ & $-2.4 \mathrm{E}-04$ & $2,259.7$ & -0.5423 \\
\hline Income & $1.17 \mathrm{E}-05$ & 31873.2 & 0.3729 \\
\hline
\end{tabular}

\section{Source: compiled by this study}

If the travel costs coefficient value of the On-Site Poisson model ( -2.4 E-04) was used for estimation, and the tourists' travel costs to Taijiang National Park were set as the price of goods, by multiplying the travel costs coefficient value with the average travel costs per person, the price elasticity of tourists to Taijiang National Park was determined to be -0.5423 (Table 6). This indicates that a 1\% increase in the tourists' travel costs to Taijiang National Park reduces the tourists' number of trips to the national park by 0.5423 . In addition, by multiplying the income coefficient value with the average income per person, the income elasticity of tourists to Taijiang National Park was determined to be 0.3729 (Table 6). Therefore, a 1\% increase in the income of tourists visiting Taijiang National Park increased their number of trips to the park by $0.3729 \%$. Because the income elasticity was between 0 and 1 , a speculation based on microeconomic theory can be made: with the improvement of people's living standards and leisure awareness, participating in the ecological tours at Taijiang National Park has become a life-related necessity. Based on this elasticity, for the tourists who visited Taijiang National Park, an increase or decrease in travel costs or income changes the demand for visiting the national park.

\section{Recreation Benefit Analysis}

The recreation benefit of Taijiang National Park was estimated based on the combined results of the TPOIS and On-Site Poisson models, as well as the aforementioned estimation results. According to the recreation benefit assessment model $[20,33]$, the CS of the $i$-th tourist can be expressed as follows:

$$
C S_{i}=\int_{P_{0}}^{\infty} e^{\beta_{0}+\beta_{1} P+\beta_{2} Y} d P=-\frac{q_{i}}{\beta_{1}} \mathrm{CS}_{\mathrm{i}}=\int_{\mathrm{C}^{0}}^{\infty} \mathrm{e}^{\beta_{0}+\beta_{1} \mathrm{c}} \mathrm{dc}=\left[\frac{\mathrm{e}^{\beta_{0}+\beta_{1} \mathrm{c}}}{\beta_{1}}\right]_{\mathrm{c}=\mathrm{c}_{0}}^{\mathrm{c} \rightarrow \infty}=-\frac{\mathrm{x}_{\mathrm{i}}}{\beta_{1}}
$$

where $P_{o} \mathrm{C}^{0}$ represents the current travel costs. The compensating variation (CV) and equivalent variation (EV) of the $i$-th tourist can be expressed as [34]:

$$
C V_{i}=-\frac{1}{\beta_{2}} \ln \left(1+\frac{\beta_{2}}{\beta_{1}} q_{i}\right)
$$




$$
E V_{i}=\frac{1}{\beta_{2}} \ln \left(1-\frac{\beta_{2}}{\beta_{1}} q_{i}\right)
$$

Table 7 Recreation benefit estimation for Taijiang National Park

\begin{tabular}{c|cc}
\hline Estimation Model & TPOIS & On-Site POIS \\
\hline Evaluation Index & 4,545 & 4,167 \\
\hline $\begin{array}{c}\text { CS } \\
\text { (NT \$/Person/Year) }\end{array}$ & $(4,135-4,955)$ & $(3,791-4,543)$ \\
\hline $\begin{array}{c}\text { 95\% Confidence Interval } \\
\text { (NT\$/Person/Year) }\end{array}$ & 4,658 & 4,272 \\
\hline $\begin{array}{c}\text { CV } \\
\text { (NT \$/Person/Year) }\end{array}$ & $(4,186-5,130)$ & $(3,838-4,706)$ \\
\hline $\begin{array}{c}\text { 95\% Confidence Interval } \\
\text { (NT\$/Person/Year) }\end{array}$ & 4,440 & 4,068 \\
\hline $\begin{array}{c}\text { EV } \\
\text { (NT \$/Person/Year) }\end{array}$ & $(4,075-4,805)$ & $(3.734-4,402)$ \\
\hline $\begin{array}{c}95 \% \text { Confidence Interval } \\
\text { (NT\$/Person/Year) }\end{array}$
\end{tabular}

Source: compiled by this study

This function was used to estimate the recreation benefit of Taijiang National Park. However, because the estimated mean recreation benefit was susceptible to extreme values, the recreation benefit for each questionnaire was first calculated, and the median recreation benefit was subsequently determined. Table 7 shows the estimation results for the recreation benefits. The CS estimated by the TPOIS model was NT $\$ 4,545 /$ person/year, and its $95 \%$ confidence interval was between NT $\$ 4.135 /$ person/year and NT $\$ 4,955 /$ person/year. The OnSite Poisson model estimated the CS to be NT $\$ 4,167 /$ person/year with a $95 \%$ confidence interval between NT\$3,791/person/year and NT\$4,534/person/year.

The results in Table 7 illustrate that the CS of the TPOIS model was higher than that of the OnSite Poisson model. According to the results of the paired sample $t$-test (Table 8), the three types of recreation benefits (CS, CV, and EV) estimated by the TPOIS model were significantly greater than those estimated by the On-Site Poisson model, indicating that the On-Site Poisson model can simultaneously correct the errors of sample truncation and endogenous stratification. By comparison, the recreation benefits are overestimated if the model is not corrected for endogenous stratification, as seen in the results of the TPOIS model.

Table 8 Paired sample $t$-tests for different recreation benefits estimated by different models

\begin{tabular}{c|ccc}
\hline $\begin{array}{c}\text { Pairwise Variable } \\
\text { Difference }\end{array}$ & M & SD & t \\
\hline $\begin{array}{c}\text { CS } \\
\text { (TPOIS-On-Site POIS) }\end{array}$ & 515.15 & 288.88 & $29.573^{* * *}$ \\
\hline $\begin{array}{c}\text { CV } \\
\text { (TPOIS - On-Site POIS) }\end{array}$ & 529.96 & 320.08 & $27.612^{* * *}$ \\
\hline $\begin{array}{c}\text { EV } \\
\text { (TPOIS - On-Site POIS) }\end{array}$ & 499.26 & 263.93 & $31.370^{* * *}$ \\
\hline
\end{tabular}


Table 9 Paired sample $t$-test for the recreation benefits in the TPOIS model

\begin{tabular}{c|ccc}
\hline $\begin{array}{c}\text { Pairwise Variable } \\
\text { Difference }\end{array}$ & M & SD & t \\
\hline $\mathrm{CS}-\mathrm{CV}$ & -289.00 & 555.03 & $-8.635^{\text {*** }}$ \\
\hline $\mathrm{CS}-\mathrm{EV}$ & 244.04 & 393.49 & $10.285^{\text {*** }}$ \\
\hline $\mathrm{CV}-\mathrm{EV}$ & 533.05 & 947.81 & $9.326^{\text {****}}$ \\
\hline
\end{tabular}

${ }^{* * *} P \leq 0.01$

Table 10 Paired sample $t$-test for the recreation benefits in the On-Site Poisson model

\begin{tabular}{c|ccc}
\hline $\begin{array}{c}\text { Pairwise Variable } \\
\text { Difference }\end{array}$ & M & SD & t \\
\hline $\mathrm{CS}-\mathrm{CV}$ & -271.20 & 522.14 & $-8.613^{* * *}$ \\
\hline $\mathrm{CS}-\mathrm{EV}$ & 228.15 & 367.34 & $10.300^{* * *}$ \\
\hline $\mathrm{CV}-\mathrm{EV}$ & 499.35 & 888.78 & $9.317^{* * *}$ \\
\hline${ }^{* * *} P \leq 0.01$ & & &
\end{tabular}

In the estimation models with the same demand function, the results derived from the three assessment indicators of recreation benefits (CS, CV, and EV) were subjected to a paired sample $t$-test (Tables 9 and 10). At a significance level of $1 \%, C V$ was significantly greater than CS in the TPOIS and On-Site Poisson models, whereas CS was significantly greater than EV. This illustrates that the relationship of the recreation benefits at the significance level of $1 \%$ in both models was $\mathrm{CV}>\mathrm{CS}>\mathrm{EV}$; that is, the three recreation benefits (CS, CV, and EV) acquired by the estimation models with the same demand function exhibited significant differences. According to the theories of microeconomy and cost-benefit analysis [35], the CV of a typical product with an increased price will be greater than its CS, whereas its CS will be greater than the EV. Therefore, when the ecotourism resources at Taijiang National Park are limited or depleted, the public is willing to pay an amount that is higher than the current average travel costs to protect or maintain the national park.

After estimating the tourists' recreation benefits, the results of this study were further compared with the empirical results of studies in Taiwan that have estimated the recreation benefits of other national parks by using TCM, as shown in Table 11. Apart from the relatively low CS in the study by Huang [16], the results of CS from the remaining studies ranged from NT\$747-NT\$10,563. The CS estimated using the On-Site Poisson model in this study was NT $\$ 4,167$, which was within the range of the aforementioned results. Further investigation revealed that the scholars constructed a demand function by using a simple linear or semilogarithmic regression model, and subsequently calculated the CS accordingly. They did not consider the fact that the number of trips is a zero-truncated, nonnegative integer and that the endogenous stratification can be generated by the data. By comparison, the On-Site Poisson model used in this study considered the errors of zero truncation and endogenous stratification; therefore, it is a suitable model for evaluating recreation benefits. 
Table 11 Results of empirical Taiwanese studies in which the TCM was adopted to estimate the recreation benefits of national parks

\begin{tabular}{ccc}
\hline Researchers & Case Study & Consumer Surplus \\
\hline & Yangmingshan National Park & NT\$10,563/person/year \\
Huang, C. H. [13] & Taroko National Park & NT\$4,213/person/year \\
& Yushan National Park & NT\$613/person/year \\
& Kenting National Park & NT\$7,746/person/year \\
\hline Lin, S. Y. [15] & Shei-Pa National Park & NT\$747/person/year \\
\hline Huang, S. H. [16] & Yangmingshan National Park & NT\$72.9/person/year \\
\hline Liao, H. H.[18] & Yangmingshan National Park & NT\$4,009/person/year \\
\hline
\end{tabular}

\section{Conclusion}

\section{CONCLUSION AND SUGGESTIONS}

An empirical model for the recreation demand of Taijiang National Park was constructed in this study by using TCM, and the TPOIS, TNB, and On-Site Poisson models were adopted to estimate the recreation benefits of the national park. The results were as follows:

i. The respondents' genders exhibited significant differences in "total annual travel costs," with the results of the independent $t$-test revealing that men had significantly greater expenses than women. Different education levels also displayed significant differences in "total annual travel costs," with the results of Scheffe post-hoc test indicating that the total annual travel costs of respondents with an education level of "master's or higher" had higher total travel costs than those with "university/college" and "general and vocation high school"-level education. Different monthly incomes also exhibited significant differences in "total annual travel costs."

ii. The On-Site Poisson model exhibited a superior goodness-of-fit and was more suitable for estimating the tourism demands of Taijiang National Park. According to the estimation by the model, the price elasticity and income elasticity of the recreation in Taijiang National Park was -0.5423 and 0.3729 , respectively, and the estimated CS was NT $\$ 4,167 /$ person/year.

iii. In terms of the recreation benefit assessment of Taijiang National Park, the three recreation benefits (CS, CV, and EV) estimated by the TPOIS model were significantly higher than those estimated by the On-Site Poisson model. In the estimation models with the same demand function, the results derived from the three recreation benefit assessment indicators (CS, CV, and EV) were analyzed by using a paired sample $t$-test, which demonstrated that the relationship of the three indicators was CV > CS > EV in the TPOIS and On-Site Poisson models at a significance level of 1\%.

\section{Suggestions}

Because Taijiang National Park has only been established for four years, it is not well known and few people have visited the park; thus, a high proportion of samples collected by this study consisted of first-time visitors, which could have affected the results. This is one of the limitations of this study. Therefore, continual collection of samples over a long period in the future is recommended for a more in-depth analysis. 


\section{APPENDIX}

The Churchill equation was used to estimate the sample size, and its equation is as follows:

$n \geq Z^{2}(\alpha / 2) \cdot p \cdot(1-p) / e^{2}$

where $n$ represents the sample size, $\alpha$ represents the significance level, $Z(\alpha / 2)$ represents the $Z$ value that causes the right tail area to be $(\alpha / 2), p$ represents the proportion of random samples, and $e$ represents the allowable estimation error. In this study, the confidence level $(1-\alpha)$ was set to be $95 \%$, and the random sample ratio $(p)$ was conservatively estimated to be

0.5. This allowed the estimated error $e$ for 275 valid samples to be:

$e=\sqrt{(1.96)^{2} \cdot(0.5)^{2} / 275}=0.059$

\section{References}

Lu, Y., Estimation of the Economic Benefit of Environmental Resources. Academia Economic Papers, 1990. 18(1): p. 93-129.

Hotelling, H., Letter to the national parks service in economic studies of outdoor recreation1947, Washington, D.C: Outdoor Recreation Review Commission.

Clawson, M., Methods of measuring the demand for and value of outdoor recreation1959, Washington, D.C: Resources for the Future Press.

Knetsch, J.L., Outdoor recreation demands and benefits. Land Economics, 1963. 39(4): p. 387-396.

McConnell, K.E., Some problems in estimating the demand for outdoor recreation. American Journal of Agricultural Economics, 1975. 57(2): p. 330-334.

Cesario, F.J. and J.L. Kentsch, A recreation site demand and benefit estimation model. Regional Studies, 1976. 10: p. 97-104.

Wilman, E.A., Hedonic prices and beach recreational values, in Advances in Applied Microeconomics, V.K. Smith, Editor 1980, JAI Press, Inc: Greenwich, CT.

Hof, J.G. and D.H. Rosenthal, Valuing the opportunity cost of travel time in recreation demand models: an application to aggregate data. Journal of leisure research, 1987. 19(3): p. 174-188.

Berstrom, J.C. and H.K. Cordell, An analysis of the demand for and value of outdoor recreation in the United States. Journal of Leisure Research, 1991. 23(1): p. 67-86.

Freeman, A.M., The measurement of environmental and resource values: theory and methods1993, Washington, D.C.: Resources for the Future Press.

Loomis, J.B. and R.G. Walsh, Recreation economic decisions: comparing benefits and costs1997, Pennsylvania: Venture Press.

Huang, R.S., Evaluation of Recreation Demand and Recreation Value of Urban Parks - An Example of Youth Park, in Institute of Urban planning, National Chang Kung University1988: Taichung.

Huang, C.H., Evaluation of Recreation Value at Taiwan National Parks. Journal of Bank of Taiwan quarterly publication, 1989. 41(3): p. 282-303.

Lin, S.Y., The Evaluation of Recreational Effects:A Case Study of Shei-Pa National Park, in Institute of Natural Resource Management. National Chung Hsing University1996: Taichung.

Chen, K.L.. (1996). The Application and Comparison of Approaches in Evaluating Economic Value of Recreation Sites - An Example of Tour-Cherng Recreation Farm. Journal of Ilan Agricultural Engineering. 12, 23-39.

Huang, S.H., Estimation of the Recreational Economic Benefit of National Park - An Example of the Yang-Ming-Sun National Park, in Institute of Urban planning, National Chang Kung University1998: Taichung.

Jeng, H.Y., W.Y. Chang, and C.T. Lin, Recreational Benefits and Time Costs of Syh-Tsao Wildlife Sanctuary: An Application of Truncated Poisson Model. Journal of Agricultural Economics, 2000. 67: p. 161-178. 
Liao, H.H., Estimation of the Travel Economic Benefit of Yang-Ming-Sun National Park, in Institute of Economics, Chinese Culture University2003: Taipei.

Chen, K.L. and Y.C. Lin, Evaluation on the Recreation Value of the I-Lan Recreational Sites. Quarterly Journal of Chinese Forestry, 2004. 37(3): p. 293-302.

Lee, C.H. and C.C. Chen, Evaluation of Motivation Styles and Economic Benefits in Festival-A Case of Yi-Lan Green Exposition. Agriculture and Economics, 2007(39): p. 137-166.

Lin, S.P., Estimation of the Beach Recreational Benefit : A Case Study of Kenting Nanwan Recreational Area, in Institute of Recreation and Geoinformatics, Chia Nan University of Pharmacy \& Science2011: Tainan.

Dong, C.M., et al., Estimation of the Recreation Benefit of Tainan First-Grade Historical Sites. Chia Nan Annual Bulletin, 2011.37(539-549).

Cheng, C.Y., The Mechanism of Wetland Conservation Management in terms of Environmental Trust in Taijang National Park, in Institute of Ecotourism, National University of Tainan2010: Tainan.

Kao, R.T., Research on Mangrove Conservation Policy of Taijiang National Park Green Tunnel, in The Graduate Institute of Political Economy, National Cheng Kung University2011: Tainan.

Chen, Y.T., Assessing a Model of Environmental Conservation Behavior on Ecological Experience Value : The Case of Taijiang National Park, in Graduate School of Leisure, Recreation and Creative Business Management, National Pingtung Institute of Commerce2011: Pingtung.

Zhuang, X.T., A Study of Developing Strategy in Taijiang National Park. Institute of Service Industries and Management., in Minghsin University of Science and Technology2010: Hsinchu.

Li, W.H., Research on Policy Cognition of Taijiang National Park- The Case Study of the Black-faced Spoonbill, in Institute of Political Economy, National Cheng Kung University2010: Tainan.

Wang, Y.C., A Case Study on the Strategies of the Sustainable Management for Ecotourism in Taijang National Park, in Institute of Ecoscience and Ecotechnology, National University of Tainan2010: Tainan.

Wang, M.R., Analysis of Stakeholder's Perception and Attitude towards Fishery Management Measures in the Sea Area of Taijiang National Park, in Institute of Ocean Technology and Marine Affair, National Cheng Kung University2011: Tainan.

Tsai, J.Y., The Study on Tourists' Intention of Taijiang National Park, in Institute of Environmental Science and Engineering, Chia Nan University of Pharmacy \& Science2011: Tainan.

Haab, T.C. and K.E. McConnell, Valuing environmental and natural resources-The econometrics of non-market valuation2002, Cheltenham, UK: Edward Elgar Press.

Chen, K.L. and Y.C. Lin, A Comparison on Recreational Values under Different Recreational Demand Functions-An Example of Ilan County. Agriculture and Economics, 2005. 34: p. 91-120.

Chen, C.M., An Evaluation on Recreation Benefits of Northern Coast Tours in Taiwan, in Institute of Applied Economics, National Taiwan Ocean University2005: Keelung.

Bockstael, N.E. and I.E. Strand, The effect of common sources of regression error on benefit estimation. Land Economics, 1987. 63(1): p. 11-20.

Huang, J.C., Exact welfare measures for a policy ban revisited, 2004, Institute of Economics, Academia Sinica: Taipei.

Shaw, D.G., et al., An Analysis of the Costs and Benefits of Environmental Protection - Theory, Method, and Application2002, Taipei: Jun Jie Academy. 